\title{
Perfiles
}

Luis Armando GonzÁleZ

\section{Los dos Bacon}

En la tradición filosófica inglesa hay dos pensadores que ocupan un lugar de primera importancia: Roger Bacon (1214-1292) y Francis Bacon (1561-1626). Por coincidencias de apellido, lo usual ha sido vincularlos familiarmente. Algo también usual ha sido confundirlos, es decir, atribuir a uno de ellos las ideas del otro. Lo primero -el parentesco- no está probado; más aún, los historiadores de la filosofía ni siquiera insinúan la posibilidad de un vínculo familiar entre ambos. Lo segundo es un poco más complicado: aunque en algunos aspectos las diferencias de ideas y planteamientos son notables, en otros aspectos hay una especie de continuidad asombrosa.

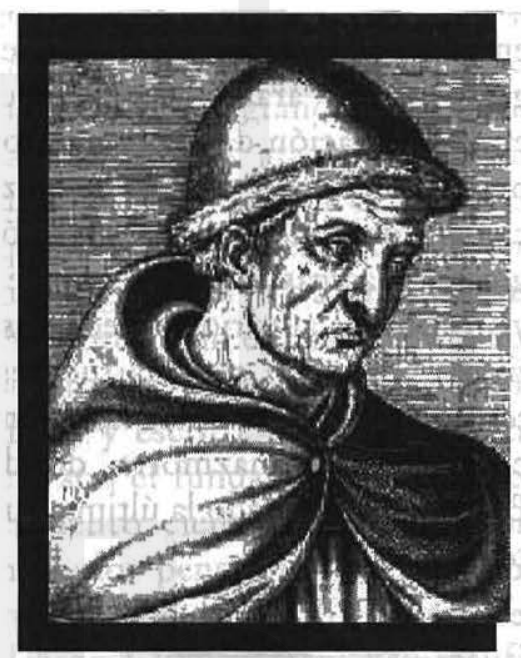

Roger Bacon (1214-1292)

Sin embargo, antes de hablar de sus ideas y de su obra, es conveniente hablar, así sea brevemente, de sus trayectorias personales. Roger Bacon nació en Ilchester, Somerset, Inglaterra, en 1214, en el cierre de la Edad Media. Fue miembro de la orden franciscana, en una época en la cual el 
neotomismo encontraba en esa orden religiosa una fuerte resistencia intelectual. Se educó en Oxford y París, donde asimiló sólidos conocimientos en matemáticas, medicina, jurisprudencia, teología y filosofía. Hacia 1247, conoció la obra de Robert Grosseteste (1168-1253), uno de los precursores de la ciencia natural moderna. Algunos historiadores sospechan que fue debido a la influencia de Grosseteste que Bacon se interesó, por un lado, en el estudio de las lenguas grie$\mathrm{ga}$, hebrea y árabe; $\mathrm{y}$, por otro, en la realización de experimentos prácticos, en los cuales se mezclaban ideas alquimistas, astrológicas y mágicas. Esto no fue bien visto por las autoridades eclesiásticas que, según algunas fuentes, terminaron por condenarlo al encierro en una mazmorra, donde Bacon habría pasado la última parte de su vida.

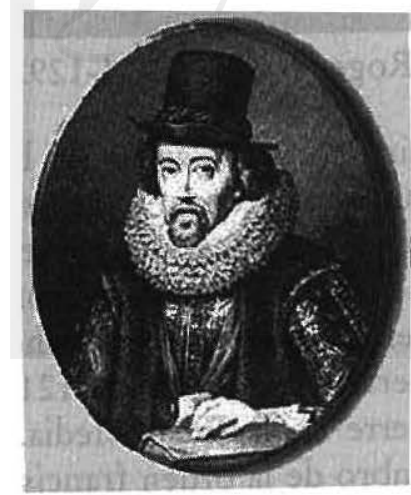

Francis Bacon (1561-1626)
Francis Bacon nació en Londres, Inglaterra, en 1561, en los albores de la modernidad occidental. Es la época no sólo del despertar del desarrollo marítimo y colonial de Inglaterra, sino también de una notable estabilidad política y florecimiento cultural, bajo el reinado de Isabel I. Sin duda, el trasfondo cultural más amplio en el que se forja su personalidad es el Renacimiento. Hijo de un guardasellos, desde muy joven, Bacon tuvo claros los dos propósitos de su vida: dedicarse a la filosofía y a la actividad política. "Puesto que me creía nacido para el servicio de la humanidad y veía como una de mis tareas la preocupación por el bien común... me pregunté qué sería lo más útil a los hombres, y para qué misiones me había dotado mejor la naturaleza. Seguí indagando, y no encontré obra más meritoria que el descubrimiento y el desarrollo de artes e inventos que sirvieran para civilizar la vida humana... Y creía también que mis deberes para con la patria exigían algo especial de mí". Fue esta segunda exigencia la que le consumió buena parte de sus energías a lo largo de su vida.

Algo digno de anotar es que Bacon decidió hacer carrera política sin recursos ni influencias. Pese a ello, desde los catorce años 
que terminó sus estudios en Cambridge, y tras una breve temporada en París, comenzó a descollar en la política hasta llegar al Parlamento. Fue también fiscal general, abogado de la corona y Lord Canciller. El éxito político apenas le daba tiempo para cumplir con el otro propósito que se había fijado: sólo marginalmente, dedicaba algún tiempo a la reflexión intelectual. Esta última sólo iba a ser una prioridad cuando al éxito político siguió el fracaso: en 1621 fue acusado y declarado culpable de recibir sobornos y participar en actos de corrupción. Con esto, su carrera política llegó a su fin. Fue indultado y, una vez libre de cargos, dedicó los cinco años que le quedaban de vida a la investigación filosófica y científica.

En cuanto a la obra intelectual de los dos Bacon cabe decir lo siguiente. Roger Bacon tenía una ambición: elaborar una enciclopedia universal -un compendiodel saber. Al hacer saber al Papa Clemente VI sus intenciones, éste le pidió una copia de la obra. En respuesta, Roger Bacon le escribió un esbozo de la misma, cuyo título era Opus maius, a la que seguiría una Opus minus y una Opus tertium. Junto con estos materiales, Bacon produjo una gramática griega, una gramática hebrea y un compendio para el estudio de la filosofía.

En síntesis, tres son los grandes postulados del pensamiento de Roger Bacon: a) los grandes maestros de la filosofía son Aristóteles, Avicena y Averroes. Pero estos filósofos han sido poco o mal entendidos porque quienes los han estudiado -los escolásticos- no conocen la lengua en que ellos han escrito. Así pues, se impone la tarea de aprender griego y árabe, si lo que se pretende es aprender de las enseñanzas de esos grandes sabios. En la mira de los ataques está, sin duda alguna, Tomás de Aquino, quien, según Roger Bacon, escribía gruesos libros sobre Aristóteles sin entender en lo absoluto lo que este último había dicho y escrito; b) las matemáticas son el fundamento del conocimiento científico. En su opinión, los pensadores escolásticos cometieron un sin fin de errores debido a su conocimiento insuficiente de las matemáticas; c) el método de conocimiento adecuado no consiste en intentar resolver los problemas apelando a alguna autoridad -es decir, haciendo deducciones lógicas a partir de unas verdades fijas y absolutas-, sino a partir de la experiencia inmediata, a partir de la observación de la naturaleza, mediante experi- 
mentos que permitan descubrir sus secretos. "Sin experiencia - sentencia Roger Bacon- no es posible saber nada suficientemente".

Los planteamientos metodológicos de Francis Bacon - recogidos en su Novum Organon- se conectan con esta última preocupación de Roger Bacon. Obviamente, en aquél el problema metodológico es abordado de un modo mucho más sistemático. Asimismo, el impacto de sus planteamientos fue de mucho mayor alcance: la tradición empirista - con sus desarrollos positivistas posteriores- tiene en Francis Bacon a uno de sus principales precursores. En una de sus formulaciones más típicas dice que "no sólo es preciso investigar y recoger el mayor número de experiencias de distinto género de las que hoy poseemos, sino que también emplear un método completamente diferente, y seguir otro orden y otra disposición en el encadenamiento y la gradación de las experiencias. Una experiencia vaga que no tiene otro objeto que ella misma... es un simple tanteo, más propio para oscurecer que para ilustrar el espíritu del hombre; pero cuando la experimentación siga reglas ciertas y avance gradualmente en un orden metódico, entonces se podrá esperar mayor resultado para las ciencias".
En un apretado resumen, sus aportes son los siguientes: a) la intención expresa de sus reflexiones es demarcar lo que él llama la «nueva ciencia natural» de la vieja teología y la vieja filosofía; b) para él el método antiguo es vicioso, especulativo: es el método de la «anticipación mental»; c) ese método conduce a prejuicios, a juicios previos que «enturbian» el acercamiento del hombre a la naturaleza; d) su método consiste, ante todo, en «purgar» la mente de todos los prejuicios, de todas las ideas preconcebidas, teorías, supersticiones y creencias, es decir, los «idolosw -idola tribus, idola specus, idola fori, idola theatrique la filosofía, la religión y la educación han inculcado a los hombres; e) limpia su mente de impurezas y prejuicios, puede el individuo acercarse a la naturaleza. Puede leer el Libro de la $\mathrm{Na}$ turaleza sin distorsionarlo; f) la naturaleza no nos engañará, puesto que lo que engaña son los prejuicios, los ídolos. Sólo tenemos que abrir los ojos; observar pacientemente y tomar registros detallados, siguiendo un firme procedimiento inductivo. Así se nos desvelará la esencia de las cosas observadas. En palabras de Karl Popper, para Francis Bacon «la observación pura, inmaculada, es buena; la observación pura no 
puede errar; la especulación y las teorías son malas, son la fuente de todo error. En particular nos tuercen la lectura del Libro de la Naturaleza, esto es, nos llevan a malinterpretar nuestras observaciones».

Con el correr de los años, los planteamientos epistemológicos y metodológicos de Francis Bacon se revelaron no sólo endebles, sino también ingenuos. Sin embargo, su influencia fue duradera $y$ aun ahora hay quienes, sin saberse sus discípulos, siguen creyendo que la ciencia consiste en recoger y clasificar datos obtenidos a través de la experiencia, es decir, que la ciencia consiste en la utilización de procedimientos inductivos para, desde las evidencias particulares arrojados por éstos, llegar a conclusiones generales. Roger es, sin duda, menos recordado que Francis. Asimismo, su influencia intelectual, del ciere de la Edad Media en adelante, ha sido menor. Con todo, le cabe el mérito de haber anticipado las preocupaciones metodológicas que casi trescientos años después iban a desvelar al segundo. Su defensa de la observación como criterio metodológico básico y su rechazo al procedimiento deductivo encuentran en Francis Bacon a su mejor continuador y exponente. 